Article

\title{
Is Binge Drinking Prevalent in Greece after the Emergence of the Economic Crisis? Assessment of This Idea Using the Theory of Planned Behavior
}

\author{
George Vlontzos ${ }^{1, *}$, Marie Noelle Duquenne ${ }^{2}$ and Spyros Niavis ${ }^{2}$ \\ 1 Department of Agriculture Crop Production and Rural Development, University of Thessaly, \\ 38446 Volos, Greece \\ 2 Department of Planning and Regional Development, University of Thessaly, 38322 Volos, Greece; \\ mdyken@uth.gr (M.N.D.); niavisspyros@gmail.com (S.N.) \\ * Correspondence: gvlontzos@agr.uth.gr; Tel.: +30-242-109-3083
}

Academic Editor: Miranda Mirosa

Received: 30 September 2016; Accepted: 22 December 2016; Published: 5 January 2017

\begin{abstract}
This paper aims to evaluate the impact of the ongoing economic crisis in Greece on alcohol consumption and binge drinking. For this reason, the Theory of Planned Behavior is being applied by using a sample of nearly 900 questionnaires. The questionnaire consists of parts trying to identify the attitude of the interviewees towards alcohol, their subjective norms of social environment, and the perceived behavioral control. This research has been implemented on a national level. The most important finding is the considerable difference in alcohol consumption compared with other countries faced similar negative economic situations. Drinking is considered as a source of pleasure and socializing. The participants' perception is that family environment and friends are not considering drinking as a non-desirable way of entertainment. As one of the major results of the survey, drinking was found to not be driven by a necessity to overcome problems related to it, which is the main difference with previous studies in others countries, like Argentina, Russia, USA, etc.
\end{abstract}

Keywords: alcohol; binge drinking; economic crisis; Theory of Planned Behavior

\section{Introduction}

The Greek economic crisis occurred after the continuous presence of a combination of two negative factors: high public debt and a high deficit. The argumentation of this outcome focuses on waste of public money, overpricing of public projects, failure to stop tax evasion, and the corruption of both political parties and public employees [1]. To a greater extent, the Greek crisis is the result of the endemic weaknesses of the State in implementing necessary structural and political reforms [2]. The social consequences of this crisis are very discouraging; the unemployment rate has increased continuously (from less than 16\% in the first quarter of 2011 to $22.6 \%$ and $27.4 \%$ in the same quarters of 2012 and 2013, respectively) and only now has a predictable ceiling. The national economy experienced a severe recession for five continuous years. The third quarter of 2012 was the worst, with a recession rate of up to $6.7 \%$ [3].

After three years of implementation of the austerity program, considerably large sectors of the Greek population now live below the poverty level, the majority being pensioners, unemployed individuals, former entrepreneurs, and immigrants [4]. At the same time, the degree of inequality in household income is increasing; the Gini index increased by 1.4 units between 2010 and 2012, from 32.9 to 34.3 [5]. In Frangos et al. [6] (p. 488), they assessed the impact of this crisis on university students in Athens, concluding, "...the Greek debt crisis is ruining the lives, dreams, and future prospects of the Greek youth." 
The vast majority of literature on alcohol consumption focuses on alcoholism, and the research approach is mainly psychological, with specific attention paid to binge drinking among young people. To prevent binge drinking among this specific group of consumers, it is important to focus on their personal attitudes. It has been effectively concluded that attitudes play a significant role in limiting alcohol consumption. Additionally, it appears that anticipated regret is the best predictor of intentions to limit drinking [7]. Similar research shows that life conditions and environment are also fundamental: a low childhood socioeconomic position measured by the education level of parents, the occupation of the parents, the number of rooms in the childhood home, and the education level of the subject all contribute to excess consumption of alcohol in adulthood [8]. Various cohort studies have drawn consistent linkages between parental socio-economic position and the use of alcohol by adolescents. Maternal education level was found to be especially important, as it is considered to be a determining factor in the engagement of young people in healthy behaviors $[9,10]$.

Consequently, for each group of the population examined, it is necessary to identify the relevant social influence variables in order to improve the efficacy of promotional campaigns discouraging binge drinking [11]. When examining binge drinking among Brazilian adolescents, Zarzar et al. [12] concluded that gender, friendship networks, and social vulnerability are strongly correlated with excessive alcohol consumption. Finally, personality traits also play an important role in alcohol use. Motivation-based preventive efforts can provide considerable assistance in reducing alcohol use among young adults who display particular personality traits [13].

The impact of various economic crises was significant on consumption trends of alcohol. In the 1990s, when Argentina experienced a serious financial crisis that led the country to default, there were noticeable changes in alcohol consumption. The most important changes were that there was a decrease in visits to bars and an increase in consumption inside homes, and there was a decrease in drink quality. Many more women than men believed that the economic crisis increased 'escape' drinking [14]. Another serious economic crisis occurred in Russia after the collapse of communism. The findings of a field research study regarding binge drinking concluded that the percentage of men rated as binge drinkers was significantly higher than the percentage of women and that there were no considerable socio-economic differences amongst binge drinkers [15,16].

The great US recession, which began in 2007, had a significant impact on drinking patterns. Men were more negatively affected by their economic problems than women [17]. There was also a small decline in alcohol use between the time periods 2006-2007 and 2008-2009, with a simultaneous increase in the prevalence of frequent binging [18].

Based on this previous research, there is no unified alcohol consumption behavior in societies experiencing economic crises. Even if the pricing of alcohol has an impact on consumption level, it has been proven that other factors are equally important, especially the per capita level of alcohol consumption and the relative ethanol share [19].

\subsection{Theoretical Background}

Most field research studies concerning health behaviors-especially binge drinking-are based on the Theory of Planned Behavior (TPB). This approach offers a reliable methodology to show how personal, psychological, and socio-economic parameters lead to binge drinking, and it assess the impact of each [7,11,20-22].

Consumer preferences and willingness to pay more for specific food attributes together represent a complex decision-making process that has been successfully conceptualized via the Theory of Reasoned Action. This theory suggests that attitudes toward behavior and subjective norms predict an individual's intention, which, in turn, predicts the behavior itself. Although this theory has been used to predict a wide range of human behaviors, it has been criticized for neglecting the role of social factors and of the environment surrounding the individual behavior [23]. It was rarely used in alcohol consumption studies. Consequently, in the Theory of Planned Behavior (TPB), Ajzen [24] presented an extension of the model that incorporates the idea of Perceived Behavioral Control as 
a predictor of both intention and behavior. Comparing the effectiveness of the TPB and the TRA in predicting intention to use alcohol, Marcoux and Shope [25] concluded that even if both approaches were effective, the TPB appeared to be more efficient than the TRA. Finally, a recent systematic review focusing on the utility of the TPB applied to alcohol consumption signifies the strong relationship among attitudes, subjective norms, and Self-Efficacy (SE) with intentions. This interrelationship shapes the framework for interventions towards reducing alcohol consumption, focusing on attitudes and subjective norms and SE aiming to reduce intentions [26].

\subsection{The Theory of Planned Behavior Model}

There are five major components of the TPB: behavior, intention, attitude, perceived social pressure, and perceived behavioral control. Each is outlined below.

Behavior: Behavior is the dependent variable in the model and refers to the action the researcher is attempting to predict.

Intention: Intention refers to the extent to which it is an individual's objective or purpose to perform the behavior (i.e., the extent to which the individual plans to engage in the behavior). Intention is thought to directly impact behavior. Attitude, perceived social pressure, and perceived behavioral control are thought to impact behavior indirectly through intention.

Attitude: Attitude refers to the valence of the individual's evaluation of performing behavior (i.e., how favorably or unfavorably an individual evaluates performing the behavior). Attitude is thought to impact intention directly and to impact behavior indirectly through intention.

Perceived social pressure: The TRA and TPB both include a "subjective norm" construct as a gauge of social approval/disapproval $[24,27]$. However, subjective norms only capture what an individual believes others want him/her to do. More recent theoretical frameworks have included both of these ideas in the form of injunctive and descriptive norms [28].

Perceived behavioral control: Perceived behavioral control refers to the extent to which the individual believes $\mathrm{s} / \mathrm{he}$ has control over the factors that facilitate or inhibit the performance of the behavior (i.e., how much the individual feels $\mathrm{s} /$ he has control over whether the behavior is performed). Perceived behavioral control is thought to directly impact both intention and behavior.

\section{Materials and Methods}

\subsection{Study Population}

The present study attempts to assess the rationale of drinking habits in a society under pressure and to propose a comprehensive analysis of alcohol behavior by implementing the Theory of Planned Behavior. This assessment is based on a field survey with a random sample of 900 consumers. Based on the Theory of Planned Behavior, the objective of the study is to develop a comprehensive analysis of alcohol behavior in Greece during an economic crisis and to test the strength of the relationship between behavioral constructs and alcohol consumption.

\subsection{Hypotheses}

Our hypotheses, which are all directly related to the TPB, are stated as follows:

Hypothesis 1. The planned behavior constructs will predict a significant portion of the variance in the intentions of alcohol consumption.

Hypothesis 2. There is a positive relationship between personal attitudes towards alcohol consumption (ATT) and the intention to participate in this behavior (INT). In other words, it is expected that individuals who consider this type of consumption enjoyable and to be a form of entertainment will be more frequent drinkers and vice versa. Different studies have effectively demonstrated that attitude—via INT—is a significant predictor for binge drinking behavior [20,29]. 
Hypothesis 3. It is suggested that subjective norms (SNs) are positively related to intention to consume (INT). The fact that an individual feels that his inner circle (family, friends, peers groups) considers alcohol consumption to be a pleasant (or unpleasant) activity should have a positive (or negative) impact on the individual's intention to consume. It is more than likely that subjective norms are influencing —via INT_alcohol drinking.

Hypothesis 4. We also assume that there is a positive relationship between the perceived behavioral control $(P B C)$ and the intention to consume (INT). In other words, the beliefs regarding the presence of "social" factors that facilitate (or impede) this type of consumption will have positive (or negative) effects on the actual behavior. These factors are mainly related to different forms of social pressure, but they can also include pressure that is self-inflicted [30].

Hypothesis 5. Finally, as stipulated in Figure 1, we consider that beyond its indirect influence through intention, perceived behavioral control (PBC) has a direct influence on drinking behavior (BEH).

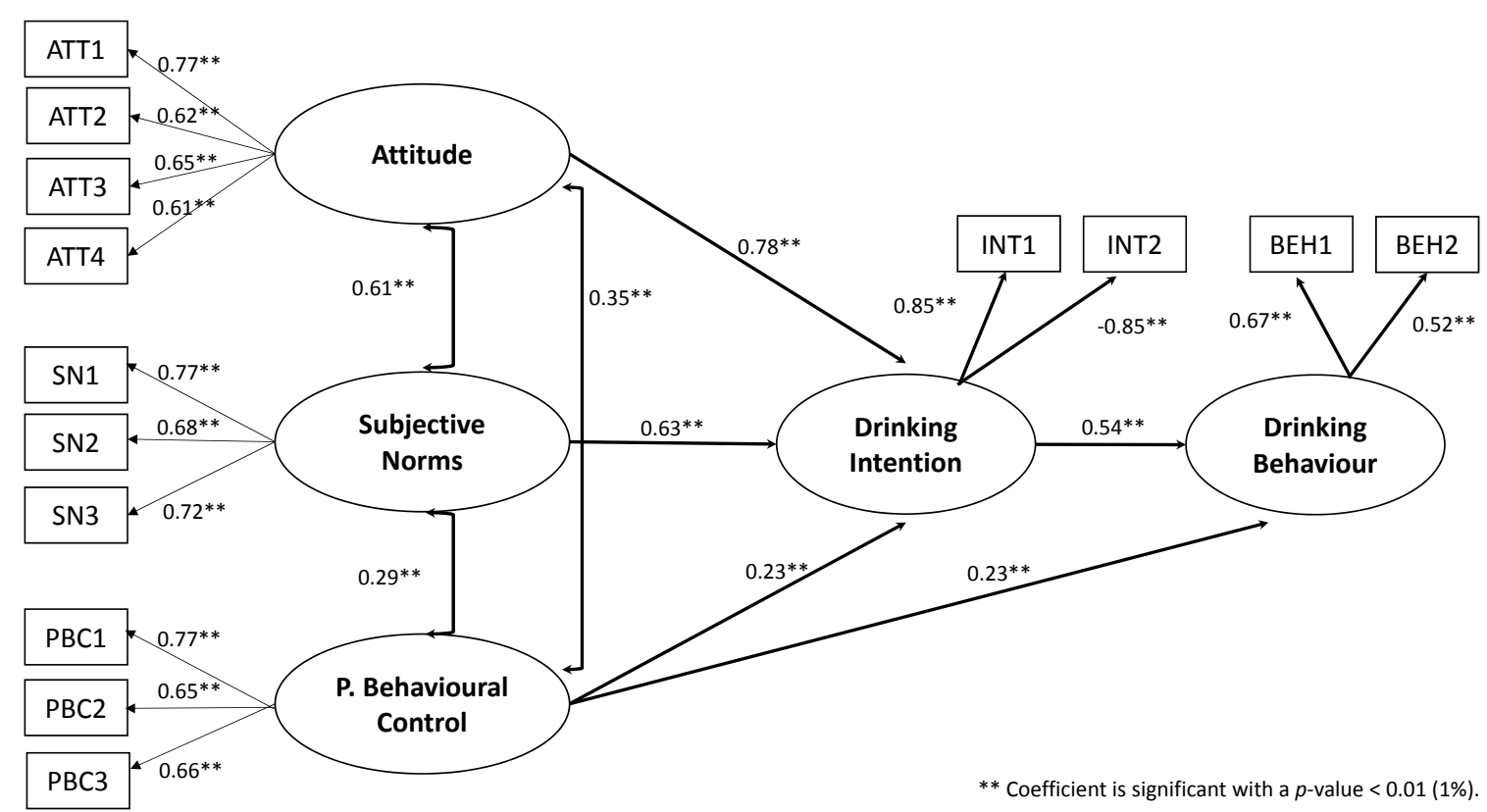

Figure 1. Results of the predictive model.

\subsection{Sample and Data Collection}

The data for testing our research model have been collected via a field survey administered to 900 consumers over 16 years of age who were randomly selected at different locations that serve alcohol. These locations were placed at both urban and rural areas of the country, covering the main Greek cities as well as rural municipalities. This classification is essential for the validity of this research, due to the fact there is considerable alcohol consumption in both areas. The survey was voluntary and absolutely confidential. The anonymous questionnaire was administered individually after obtaining verbal consent from each participant and providing the necessary clarifications with regards to questionnaire content. In case of refusal, the interviewer had to choose another participant of the same sex and age class. Once the questionnaire was completed, the participant returned it to the interviewer. The data were collected on both weekdays and weekends.

To obtain a representative sample with appropriate confidence level, the sample size was set at 900 participants, corresponding to a confidence interval of $95 \%$ and margin error about $3 \%$. Eight hundred seventy-four (874) completed questionnaires were retained for the statistical analysis, representing a loss of $2.9 \%$, which is reasonably limited. The respondents ranged in age from 16 to 75 (mean of 38 and standard deviation of 13.88), with $56 \%$ males and $44 \%$ females. They also represented 
diverse education levels ( $9 \%$ with lower secondary education level, $45 \%$ with upper secondary education level, and $46 \%$ with post-secondary) and occupations (60\% are employees or self-employed).

\subsection{Structure of the Questionnaire and Description of Items}

The questionnaire was divided into three parts. The first part captured socio-demographic characteristics. The second part was devoted to the respondent's drinking intention and behavior, including frequency, consumption levels, and consumption locations. The third part included all questions related to TPB constructs to measure attitude, subjective norms, and behavioral control.

For each construct, different items were measured using a five-point ranking scale, ranging from 1 "strongly disagree" to 5 "strongly agree".

(a) "Attitude" is composed of four items ranging from "strongly bad" to "strongly good". Through these four items, respondents have to assess the consumption of alcohol as a normal habit (ATT1), as a healthy behavior (ATT2), as a source of pleasure (ATT3), and finally as a hazardous behavior (ATT4).

(b) "Subjective norms" are defined by three items ranging from "strongly disagree" to "strongly agree". These items concerned the impact of the social environment (family and friends) on alcohol use (SN1), how much the social environment impacted more frequent use of alcohol (SN2) and the impact of the social environment on the relationship between alcohol use and socializing (SN3) [7].

(c) "Behavioral control" is also composed of three items using the same scale as subjective norms. These items were used to measure "Perceived Behavioral Control". The first concerns the "social pressure", which leads to or encourages drinking alcohol (PBC1). The two other items are related to self-control, which is analyzed as follows:

- The ability to refuse to drink when there is motivation to do so from friends or peers (PBC2) and

- The use of alcohol to overcome financial and other social problems due to the economic crisis (PBC3).

The number of items was deliberately limited so that respondents would feel comfortable filling out the questionnaire. The survey was conducted on a voluntary basis, so we considered it appropriate to limit the completion time. Nevertheless, a minimum of three items is a basic guaranty for adequate reliability [31].

(d) Two other items allowed us to evaluate the drinking intention. The first one indicates to what extent the participant prefers to go out with the clear intention of drinking alcohol by choosing a place devoted to alcoholic consumption (INT1). The second indicates to what extent the participant intends to drink (INT2) when going out to other places of entertainment (as restaurant). These two items are measured on a scale from 1 "not at all" to 5 "absolutely".

(e) Finally, the drinking behavior was assessed via two open-ended questions: "How many times a month you drink alcohol?" (BEH1) and "On average, how many drinks do you consume each time?" (BEH2).

\subsection{Analytic Plan of the Study}

While the survey was given to 900 participants, the descriptive statistical analysis showed that 26 questionnaires present quite systematically missing values and inconsistent responses with regards to drinking behavior. Consequently, the data analysis was conducted on a final sample of 874 participants (the loss of information was lower than $3 \%$ ).

Initially, we used exploratory factorial analysis (EFA) and reliability tests in SPSS in order to initially validate the survey construction and to measure the appropriate latent variables: Attitude, 
Perceived Norms, and Perceived Behavior Control. EFA was implemented with the 10 observed variables. This method is especially pertinent when there is no a priori knowledge of how many factors or constructs are needed to explain the relationship between the set of indicators or items [32,33]. It also helps verify the relevance of the suggested constructs.

Next, as suggested by [34], a two-step approach was used to evaluate whether the suggested model fit our data.

The first step concerns the implementation of confirmatory factorial analysis (CFA), through which it is possible to estimate the measurement component of the constructs. The CFA implemented through LISREL was specified as follows: the items (observed variables) have been loaded on their underlying construct, and inter-construct correlations were allowed. Their corresponding measurement errors have also been estimated.

To verify that the structure of the model is acceptable, three categories of tests were examined. The first concerns the absolute fit indices that we used to examine to what extent our model fit the sample data. A good approximation of the data is based on the Chi-squared test; a non-significant chi-square leads to the non-rejection of the model ( $p$-value $>0.05$ ) and suggests a good approximation; otherwise, we have "a lack of fit" [35]. Because this test is sensitive to sample size [36,37], we pay more attention to the Chi-square to degree of freedom ratio, whereby a ratio less than 0.5 is acceptable and a ratio less than 0.2 is considered most pertinent [33]. The residual-based index RMSEA (root mean square error of approximation) is the second important index for model evaluation. It indicates how well the model fits the population covariance matrix. Values larger than 0.10 indicate a very poor fitting model [38]. There is no longer a consensus about the upper limit of 0.07 [39]. We considered the goodness of fit statistic (GFS) and the adjusted goodness of fit statistic (AGFS), where values greater than 0.90 indicate well-fitting models. We also considered the root mean square residual (RMR) and the standardized root mean square residual (SRMR).

The second category of tests is related to the incremental fit indexes in which a chi-square value is compared to a baseline mode. We examined common reported fit indexes such as normed fix index (NFI) and comparative fit index (CFI). For these tests, we followed the recommendations of [40].

Finally, the third category is related to parsimony fit indices: the parsimony goodness of fit (PGF) and the parsimonious normed fit index (PNFI) proposed by [35]. Even if no threshold levels have been proposed, the authors suggest that values over 0.90 are desirable.

Second step: After confirming a good approximation of the data, we proceed with the predictive model. The objective of this is to determine to what extent the latent variables were good predictors in explaining alcohol consumption. In this step, the measurement and structural components were simultaneously estimated. The model's specification can be summarized as follows: each of the constructs (latent variables) was specified to predict its respective items (observed variables). Then, the three constructs were allowed to freely inter-correlate with one another, and all were set to predict "drinking intention". Measurement errors and disturbance terms representing all the omitted causes of the endogenous variables were also estimated. Finally, the number of estimated parameters was not allowed to exceed the number of unique data points. This is a necessary condition for estimating a solution.

\section{Results}

Mean scores with standard deviations concerning the items measuring attitude, subjective norms, and behavioral control as well as drinking intention are reported on Table 1. The consumption of alcohol is obviously a source of pleasure and a quite normal habit while it appears that respondents do not really agree that the use of alcohol contributes to overcoming financial and social problems due to the crisis. This item presents the lowest mean scores among the 10 items of the TPB constructs. 
Table 1. Mean scores of TPB items and drinking intention.

\begin{tabular}{lcccccccc}
\hline & \multicolumn{2}{c}{ Total } & \multicolumn{2}{c}{ Men } & \multicolumn{2}{c}{ Women } & $\begin{array}{c}\text { Mean Difference } \\
\text { between Men } \\
\text { and Women }\end{array}$ \\
\cline { 2 - 8 } & Mean & Std. Dev. & Mean & Std. Dev. & Mean & Std. Dev. & $0.26^{\text {a }}$ \\
\hline Normal habit (ATT1) & 3.51 & 1.053 & 3.62 & 1.004 & 3.36 & 1.097 & $0.17^{\text {a }}$ \\
\hline Healthy behavior (ATT2) & 2.83 & 1.000 & 2.91 & 1.013 & 2.74 & 0.974 & 0.12 \\
\hline Source of pleasure (ATT3) & 4.11 & 0.991 & 4.16 & 0.965 & 4.04 & 1.021 & $0.30^{\text {a }}$ \\
\hline Hazardous attitude (ATT4) & 3.07 & 1.061 & 3.20 & 1.056 & 2.90 & 1.044 & 0.03 \\
\hline $\begin{array}{l}\text { Impression of the social environment as } \\
\text { regards alcohol use (SN1) }\end{array}$ & 3.60 & 1.085 & 3.61 & 1.084 & 3.58 & 1.088 & 0.10 \\
\hline Motivation from the social environment (SN2) & 2.94 & 1.092 & 2.98 & 1.105 & 2.88 & 1.075 & $0.15^{\mathrm{b}}$ \\
\hline $\begin{array}{l}\text { Environment's appraisal regarding alcohol } \\
\text { uses and socializing (SN3) }\end{array}$ & 3.49 & 1.140 & 3.55 & 1.145 & 3.41 & 1.130 & $0.32^{\mathrm{a}}$ \\
\hline Social pressure encouraging to drink (PBC1) & 3.19 & 1.441 & 3.33 & 1.432 & 3.01 & 1.435 & $0.33^{\mathrm{a}}$ \\
\hline Ability to refuse to drink (PBC2) & 3.06 & 1.328 & 3.20 & 1.350 & 2.87 & 1.277 & 0.10 \\
\hline Use of alcohol to overcome problems (PBC3) & 2.53 & 1.369 & 2.57 & 1.389 & 2.47 & 1.342 & 0.13 \\
\hline $\begin{array}{l}\text { Clear intention to drink alcohol by choosing } \\
\text { a place devoted to this consumption (INT1) }\end{array}$ & 2.82 & 1.126 & 2.88 & 1.191 & 2.74 & 1.033 & $-0.28^{\text {a }}$ \\
\hline $\begin{array}{l}\text { Intention to drink in other places of } \\
\text { entertainment (INT2) }\end{array}$ & 2.21 & 1.393 & 2.09 & 1.398 & 2.37 & 1.373 & \\
\hline
\end{tabular}

Std. Dev., Standard Deviation; ${ }^{\text {a }}$ Mean difference significant with $p$-value $<0.01$; $^{\text {b }}$ Mean difference significant with $p$-value $<0.05$.

We initially implemented a principal component analysis (PCA) with the varimax rotation method in order to validate our theoretical constructs and to examine the dimensions of the scale. All of the extracted communality coefficients are higher than $52 \%$ (Table 2), while the Kaiser-Meyer-Olkin (KMO) has an "excellent" value (0.805) [41]. These initial results reflect the degree of synergy among the initial variables and seem to confirm the construct validity of the model. The results reinforce our hypothesis about the existence of the three distinct constructs (Attitude, Subjective Norms, and Behavioral Control), which represent a cumulative total variance of $62.7 \%$.

Table 2. Exploratory factor analysis.

\begin{tabular}{lcccc}
\hline \multirow{2}{*}{ Items } & $\begin{array}{c}\text { Extracted } \\
\text { Communalities }\end{array}$ & \multicolumn{2}{c}{ Factors-Latent Variables } \\
\cline { 3 - 5 } & & $\mathbf{1}$ & $\mathbf{2}$ & $\mathbf{3}$ \\
\hline Normal habit (ATT1) & 0.681 & $\mathbf{0 . 7 9 8}{ }^{*}$ & 0.156 & 0.139 \\
\hline Source of pleasure (ATT3) & 0.566 & $\mathbf{0 . 7 3 3}$ & 0.145 & 0.088 \\
\hline Healthy behavior (ATT2) & 0.553 & $\mathbf{0 . 7 2 0}$ & 0.187 & 0.016 \\
\hline Hazardous attitude (ATT4) & 0.521 & $\mathbf{0 . 6 8 3}$ & 0.204 & 0.114 \\
\hline Motivation from the social environment (SN2) & 0.698 & 0.144 & $\mathbf{0 . 8 2 2}$ & 0.053 \\
\hline Impression of the social environment as regards alcohol use (SN1) & 0.697 & 0.265 & $\mathbf{0 . 7 9 1}$ & 0.038 \\
\hline Environment's appraisal regarding alcohol uses and socializing (SN3) & 0.665 & 0.221 & $\mathbf{0 . 7 6 9}$ & 0.156 \\
\hline Use of alcohol to overcome problems (PBC3) & 0.603 & 0.008 & 0.039 & $\mathbf{0 . 8 1 8}$ \\
\hline Ability to refuse to drink (PBC2) & 0.615 & 0.109 & 0.136 & $\mathbf{0 . 7 6 5}$ \\
\hline Social pressure encouraging to drink (PBC1) & 0.671 & 0.163 & 0.045 & $\mathbf{0 . 7 5 8}$ \\
\hline \% of Total variance explained by each factor & & 35.1 & 16.1 & 11.5 \\
\hline Cumulative variance & & 35.1 & 51.2 & 62.7 \\
\hline
\end{tabular}

* Data in bold: Significant Attributes.

The reliability tests confirm that the measure of the three constructs is significant. The value of the Cronbach's $\alpha$ can be considered satisfactory for each one of the three constructs, even though the Behavioral Control (with $\alpha$ approximately 0.700 ) seems to be less reliable compared to the other two 
(Table 3). The corrected item-total correction (CITC) value ranges from 0.499 to 0.628 . In conformity with the cut-off value of 0.500 proposed by [42], any observed variables (items) should be rejected from further analysis. It is also interesting to observe that alcohol consumption is primarily considered to be a source of pleasure (ATT3). This item has the highest mean value (4.11 on a scale from 1 to 5), whereas using alcohol to relieve anxiety and forget personal problems (PBC3) has the lowest score.

Table 3. Results of reliability analysis.

\begin{tabular}{|c|c|c|c|c|c|c|}
\hline Constructs & Cronbach $\alpha$ & Items & Mean Value * & Std Dev. & CITC* & $\begin{array}{l}\text { Cronbach's If } \\
\text { Item Deleted }\end{array}$ \\
\hline \multirow{4}{*}{ Attitude } & \multirow{4}{*}{0.757} & Normal habit (ATT1) & 3.51 & 1.053 & 0.628 & 0.658 \\
\hline & & Healthy behavior (ATT2) & 2.83 & 1.002 & 0.540 & 0.708 \\
\hline & & Source of pleasure (ATT3) & 4.11 & 0.991 & 0.527 & 0.715 \\
\hline & & Hazardous attitude (ATT4) & 3.07 & 1.060 & 0.529 & 0.717 \\
\hline \multirow{3}{*}{$\begin{array}{l}\text { Subjective } \\
\text { norms }\end{array}$} & \multirow{3}{*}{0.768} & $\begin{array}{l}\text { Impression of the social } \\
\text { environment as regards alcohol } \\
\text { use (SN1) }\end{array}$ & 3.60 & 1,085 & 0.623 & 0.662 \\
\hline & & $\begin{array}{l}\text { Motivation from the social } \\
\text { environment (SN2) }\end{array}$ & 2.94 & 1.092 & 0.586 & 0.702 \\
\hline & & $\begin{array}{l}\text { Environment's appraisal } \\
\text { regarding alcohol uses and } \\
\text { socializing (SN3) }\end{array}$ & 3.49 & 1.14 & 0.592 & 0.697 \\
\hline \multirow{3}{*}{$\begin{array}{l}\text { Behavioral } \\
\text { control }\end{array}$} & \multirow{3}{*}{0.699} & $\begin{array}{l}\text { Social pressure encouraging to } \\
\text { drink (PBC1) }\end{array}$ & 3.19 & 1,429 & 0.499 & 0.629 \\
\hline & & Ability to refuse to drink (PBC2) & 3.05 & 1.332 & 0.511 & 0.613 \\
\hline & & $\begin{array}{l}\text { Use of alcohol to overcome } \\
\text { problems (PBC3) }\end{array}$ & 2.44 & 1.348 & 0.536 & 0.580 \\
\hline
\end{tabular}

${ }^{*}$ Each item is defined on a range scale from 1 to 5 , where the value 5 corresponds to strong agreement.

The confirmatory factor model based on the five latent variables of the TPB (including intention and behavior) fits the data well (Table 4). The chi-square-to-degrees of freedom ratio is an acceptable $2.8\left(X^{2}=189.22\right.$ and $\left.d f=67\right)$, but this index is subject to limitations and is sensitive to the sample size. Nevertheless, the RMSEA, which is regarded as "one of the most informative fit indexes" [43], is equal to 0.046 with a $90 \%$ percent confidence interval of 0.038 to 0.054 . This level indicates a good fit $[38,39,41]$.

Table 4. Evaluation of CFA.

\begin{tabular}{ccc}
\hline Category of Fit Indexes & Goodness of Fit & Cut-Off \\
\hline \multicolumn{3}{c}{ 1. Absolute indexes } \\
\hline Chi square/df & 2.825 & $<2$ good, $<5$ acceptable \\
RMSEA & 0.046 & $\leq 0.06$ \\
GFI & 0.970 & $\geq 0.95$ \\
AGFI & 0.953 & $\geq 0.90$ \\
SRMR & 0.034 & $\leq 0.05$ \\
\hline \multicolumn{3}{c}{} \\
\hline NNFI & 2. Incremental indexes \\
CFI & 0.966 & $\geq 0.95$ \\
\hline PNFI & 0.975 & $\geq 0.95$ \\
\hline
\end{tabular}

With regards to the other absolute fit indexes that are generally examined in similar research, they confirm - in accordance with the common accepted cut-offs-that the proposed model fits the data well (see cut-off levels in Table 4). In this table, we observed that the incremental (relative) fit indices and the parsimony fit indices are a good fit. 
Even if all item loadings were revealed to be statistically significant $(p<0.01)$, it appears that some of them are better reflected by their associated construct (Table 5).

Table 5. Measurement equations.

\begin{tabular}{|c|c|c|c|c|c|}
\hline Component & Items & $\begin{array}{l}\text { Unstandardized } \\
\text { Estimates }\end{array}$ & $\begin{array}{l}\text { Standardized } \\
\text { Estimates }\end{array}$ & $t$-Values & $R^{2}$ \\
\hline \multirow{4}{*}{ Attitude (ATT) } & Normal habit (ATT1) & $0.81 * *$ & 0.77 & 23.70 & 0.59 \\
\hline & Healthy behavior (ATT2) & $0.62 * *$ & 0.62 & 18.27 & 0.39 \\
\hline & Source of pleasure (ATT3) & $0.65^{* *}$ & 0.65 & 19.27 & 0.42 \\
\hline & Hazardous attitude (ATT4) & $0.65^{* *}$ & 0.61 & 17.83 & 0.37 \\
\hline \multirow{3}{*}{$\begin{array}{l}\text { Subjective } \\
\text { norms (SN) }\end{array}$} & $\begin{array}{l}\text { Impression of the social environment as } \\
\text { regards alcohol use (SN1) }\end{array}$ & $0.83^{* *}$ & 0.77 & 23.09 & 0.59 \\
\hline & Motivation from the social environment (SN2) & $0.75^{* *}$ & 0.68 & 20.16 & 0.47 \\
\hline & $\begin{array}{l}\text { Environment's appraisal regarding alcohol } \\
\text { uses and socializing (SN3) }\end{array}$ & $0.82 * *$ & 0.72 & 21.52 & 0.52 \\
\hline \multirow{3}{*}{$\begin{array}{c}\text { Perceived } \\
\text { behavioral } \\
\text { control (PBC) }\end{array}$} & Social pressure encouraging to drink ( $\mathrm{PBC} 1$ ) & $0.94^{* *}$ & 0.65 & 17.36 & 0.42 \\
\hline & Ability to refuse to drink (PBC2) & $0.89 * *$ & 0.67 & 17.84 & 0.45 \\
\hline & Use of alcohol to overcome problems (PBC3) & $0.91 * *$ & 0.66 & 17.66 & 0.44 \\
\hline \multirow{2}{*}{ Intention (INT) } & $\begin{array}{l}\text { Clear intention to drink alcohol by choosing a } \\
\text { place devoted to this consumption (INT1) }\end{array}$ & $0.96 * *$ & 0.85 & 13.96 & 0.72 \\
\hline & $\begin{array}{l}\text { Intention to drink in other places of } \\
\text { entertainment (INT2) }\end{array}$ & $0.68^{* *}$ & -0.84 & -10.88 & 0.24 \\
\hline \multirow[t]{2}{*}{ Behavior (BEH) } & $\begin{array}{l}\text { Frequency of alcohol consumption by } \\
\text { month (BEH1) }\end{array}$ & $2.70^{* *}$ & 0.67 & 12.87 & 0.45 \\
\hline & Average consumption each time (BEH2) & $1.43 * *$ & 0.52 & 11.35 & 0.27 \\
\hline
\end{tabular}

Concerning the attitude of the consumers with regards alcohol use, we observe a positive association with the four relative items. The highest association is related to the first item (normal habit), which confirms that in general, Greek consumers consider drinking to be a source of pleasure and socializing.

With regards the subjective norms (second construct), there is a positive relationship with each of the three examined items. The participants' perception that family, environment, and friends do not consider drinking a desirable form of entertainment reinforces their own perception.

The "behavioral control" (PBC) is positively associated with the three observed items. This result is especially interesting because it shows that even in a period of deep economic crisis, drinking is not driven by a necessity to overcome related problems.

The intention to drink is significantly and positively related to the desire to go to places devoted to alcohol consumption (INT1). It is negatively related to the desire to go to other entertainment venues (INT2). This result suggests that entertainment is not always associated with the use of alcohol.

Some modifications were suggested in order to obtain a model that better fits the data. The suggestions must be treated with caution, however, because statistical improvement is not a goal in and of itself. In the present case, the two proposed modifications concern the "Environment's appraisal regarding alcohol uses and socializing" (SN3), which could also be reflected by the Perceived Behavior Control (PBC), while the "Use of alcohol to overcome problems" (PBC3) should also be reflected by the Attitude construct. Examining the meaning of these two items, it appears that these relations are quite meaningful:

The fact that the interviewee believes that the social environment positively correlates with the consumption of alcohol while socializing can be considered a social control parameter. This signifies that Greek society is not opposed to alcohol consumption.

Excess alcohol consumption is not socially accepted as a means to overcome financial and other problems; this signifies that binge drinking is not an acceptable social behavior. 
The revised model better fits the data, but the improvement in the goodness of fit is very limited (chi-square $=164.83, d f=65$, ratio $=2.56)$ with RMSEA $=0.042(90 \%$ CI: 0.034, 0.050).

Considering that this statistical improvement generated by the modified model is limited, we deliberately chose to keep the original theoretical model. Consequently, we examined to what extent the three constructs predict the drinking intention of the participants and a fortiori the participants' drinking consumption. The results are once again significant with $X^{2} / \mathrm{df}=2.62\left(X^{2}=188.320, d f=72\right)$, RMSEA $=0.044(90 \% \mathrm{CI}=0.037-0.051)$, and GFI $=0.972$. The incremental $/$ comparative indices are also high, corroborating the good fit of the predictive model $(\mathrm{NNFI}=0.969, \mathrm{CFI}=0.978)$.

The correlation between the constructs revealed that they are all positively correlated with each other, as we hypothesized (Figure 1). The highest correlation is between Attitude and Subjective Norms $\left(r=0.61^{* *}\right)$, while the weakest is observed between Subjective Norms and Perceived Behavior Control $\left(r=0.29^{* *}\right)$.

The intention to drink is mainly linked with the perception that the consumption of alcohol is pleasurable, while it appears that most of the respondents do not consider consumption to be bad for their health. This can also partly be explained by the fact that respondents generally believe they are able to control their consumption and resist social pressure.

\section{Conclusions}

This research focuses on assessing the alcohol consumption trends in Greek society. This particular timing is suitable for monitoring such behaviors due to the ongoing economic crises the country has faced for the last four years. The most important findings prove that although alcohol consumption is a socially acceptable behavior, binge drinking is not acceptable on both social and personal levels. Despite the fact that, in similar situations of social stress due to financial problems, there was an increase in alcohol consumption, Greek society does not condone binge drinking. This research also proves the considerable impact of the family as an obstacle for avoiding socially non-acceptable behaviors, something that characterizes conservative societies, like the Greek one. The implementation of the TPB verifies these findings, concurrently providing the opportunity to compare social reactions among different societies facing financial problems overtime. Focusing on the spatial dimension of this study, there were not differentiated consumer behaviors between inhabitants of urban and rural places. Taking into consideration the recent review about the implementation of TPB for alcohol studies, the findings of this research empower the utility of this model, justifying its appropriateness for similar studies [26]. This study provides useful information for both alcoholic drink manufacturers and policy makers for modifying their activities in a market deeply affected by continuous financial problems, unemployment, and social isolation.

Author Contributions: George Vlontzos conceived and designed the field research; Marie Noelle Duquenne and Spyros Niavis analyzed the data; George Vlontzos wrote the paper.

Conflicts of Interest: The authors declare no conflict of interest.

\section{References}

1. Papadakis, K. Restructuring Enterprises through Social Dialogue: Socially Responsible Practices in Times of Crisis; Working Paper No. 19; International Labour Organization (ILO): Geneva, Switzerland, 2010.

2. Mitsopoulos, M.; Pelagidis, T. Analysis of the Greek Economy: Rent Seeking and the Reforms; Papazisis: Athens, Greece, 2006.

3. ELSTAT; Hellenic Statistical Service. Monthly Bulletins; ELSTAT: Athens, Greece, 2013.

4. Centre of Planning and Economic Research. Greek Economic Outlook; Centre of Planning and Economic Research: Athens, Greece, 2012.

5. ELSTAT; Hellenic Statistical Service. Households' Income and Living Conditions Survey. Press Release. Athens. 2012. Available online: http://www.statistics.gr/portal/page/portal/ESYE/BUCKET/A0802/ PressReleases/A0802_SFA10_DT_AN_00_2012_06_F_GR.pdf (accessed on 5 September 2016). 
6. Frangos, C.; Frangos, C.; Sotiropoulos, I.; Orfanos, V.; Toudas, K.; Gkika, E. The Effects of the Greek Economic Crisis on Eating Habits and Psychological Attitudes of Young People: A Sample Survey among Greek University Students. In Proceedings of the World Congress on Engineering (WCE), London, UK, 4-6 July 2012; Volume I. Available online: http:/ /www.iaeng.org/publication/WCE2012/WCE2012_485--489.pdf (accessed on 5 September 2016).

7. Cooke, R.; Sniehotta, F.; Schuz, B. Predicting binge-drinking behavior using an extended TBP: Examining the impact of anticipated regret and descriptive norms. Alcohol Alcohol. 2007, 42, 84-91. [CrossRef] [PubMed]

8. Yang, S.; Lynch, J.W.; Raghunathan, T.E.; Kauhanen, J.; Salonen, J.T.; Kaplan, G.A. Socioeconomic and Psychosocial Exposures across the Life Course and Binge Drinking in Adulthood: Population-based Study. Am. J. Epidemiol. 2007, 165, 184-193. [CrossRef] [PubMed]

9. Melotti, R.; Heron, J.; Hickman, M.; Macleod, J.; Araya, R.; Lewis, G. Adolescent Alcohol and Tobacco Use and Early Socioeconomic Position: The ALSPAC Birth Cohort. Pediatrics 2011, 127, 948-955. [CrossRef] [PubMed]

10. Gauffin, K.; Hemmingsson, T.; Hjern, A. The effect of childhood socioeconomic position on alcohol-related disorders later in life: A Swedish national cohort study. J. Epidemiol. Commun. Health 2013, 67, 932-938. [CrossRef] [PubMed]

11. Johnston, K.L.; White, K.M. Binge-drinking: A test of the role of group norms in the Theory of Planned Behavior. Psychol. Health 2003, 18, 63-77. [CrossRef]

12. Zarzar, P.M.; Jorge, K.O.; Oksanen, T.; Vale, M.P.; Ferreira, E.F.; Kawachi, I. Association between binge drinking, type of friends and gender: A cross-sectional study among Brazilian adolescents. BMC Public Health 2012, 12, 257. [CrossRef] [PubMed]

13. Kuntsche, E.; von Fischer, M.; Gmel, G. Personality factors and alcohol use: A mediator analysis of drinking motives. Personal. Individ. Differ. 2008, 45, 796-800. [CrossRef]

14. Munne, M.I. Social consequences of alcohol consumption in Argentina. In Alcohol, Gender and Drinking Problems: Perspectives from Low and Middle Income Countries; Obot, I.S., Room, R., Eds.; World Health Organization, Department of Mental Health and Substance Abuse: Geneva, Switzerland, 2005.

15. Bobak, M.; Mckee, M.; Rose, R.; Marmot, M. Alcohol consumption in a national sample of the Russian population. Addiction 1999, 94, 857-866. [CrossRef] [PubMed]

16. McKee, M. Alcohol in Russia. Alcohol Alcohol. 1999, 34, 824-829. [CrossRef] [PubMed]

17. Richman, J.A.; Rospenda, K.M.; Johnson, T.P.; Ilk Cho, Y.; Vijayasira, G.; Cloninger, L.; Wolff, J.M. Drinking in the Age of the Great Recession. J. Addict. Dis. 2012, 31, 158-172. [CrossRef] [PubMed]

18. Bor, J.; Basu, S.; Coutts, A.; McKee, M.; Stuckler, D. Alcohol use during the Great Recession of 2008-2009. Alcohol Alcohol. 2013, 48, 343-348. [CrossRef] [PubMed]

19. Fogarty, J. The nature of the demand for alcohol: Understanding elasticity. Br. Food J. 2006, 108, $316-332$. [CrossRef]

20. Glassman, T.; Braun, R.E.; Dodd, V.; Miller, J.M.; Miller, E.M. Using Theory of Planned Behavior to explain the drinking motivations of social, high-risk and extreme drinkers on game day. J. Commun. Health 2010, 35, 172-181. [CrossRef] [PubMed]

21. Hutching, K.; Lac, A.; LaBrie, J.W. An application of the theory of Planned Behavior to Sorority Alcohol Consumption. Addict. Behav. 2008, 33, 538-551.

22. Norman, P.; Armitage, C.J.; Quigley, C. The theory of planned behavior and binge drinking: Assessing the impact of binge drinker prototypes. Addict. Behav. 2007, 32, 1753-1758. [CrossRef] [PubMed]

23. Werner, P. Reasoned action and planned behavior. In Middle Range Theories: Application to Nursing Research; Peterson, S.J., Bredow, T.S., Eds.; Lippincott, Williams \& Wilkins: Philadeliphia, PA, USA, 2004; pp. 125-147.

24. Ajzen, I. The Theory of Planned Behavior. Organ. Behav. Hum. Decis. Process. 1991, 50, 179-211. [CrossRef]

25. Marcoux, B.C.; Shope, J.T. Application of the Theory of Planned Behavior to adolescent use and misuse of alcohol. Health Educ. Res. 1997, 12, 323-331. [CrossRef]

26. Cooke, R.; Dahdah, M.; Norman, P.; French, D. How well does the theory of planned behavior predict alcohol consumption? A systematic reviewand meta-analysis. Health Psychol. Rev. 2016, 10, 148-167. [CrossRef] [PubMed]

27. Fishbein, M.; Ajzen, I. Predicting and understanding consumer behavior: Attitude-behavior correspondence. In Understanding Attitudes and Predicting Social Behavior; Ajzen, I., Fishbein, M., Eds.; Prentice Hall: Englewood Cliffs, NJ, USA, 1980; pp. 148-172. 
28. Fishbein, M.; Ajzen, I. Belief, Attitude, Intention, and Behavior: An Introduction to Theory and Research; Addison-Wesley: Reading, MA, USA, 1975.

29. Hagger-Johnson, G.; Whiteman, M.C. Conscientiousness facets and health behaviors: A latent variable modeling approach. Personal. Individ. Differ. 2007, 43, 1235-1245. [CrossRef]

30. Montano, D.E.; Kasprzyk, D. The Theory of Reasoned Action and the Theory of Planned Behavior. In Health Behavior and Health Education; Glanz, K., Rimer, B., Lewis, F.M., Eds.; Jossey-Bass: San Francisco, CA, USA, 2002; pp. 67-98.

31. Nunnally, J.C. Psychometric Theory, 2nd ed.; McGraw-Hill: New York, NY, USA, 1978.

32. Gorsuch, R.L. Factor Analysis, 2nd ed.; Lawrence Erlbaum Associates: Hillsdale, NJ, USA, 1983.

33. Tabachnick, B.G.; Fidell, L.S. Using Multivariate Statistics, 5th ed.; Pearson Allyn \& Bacon: Upper Saddle River, NJ, USA, 2007.

34. Anderson, J.C.; Gerbing, D.W. Structural Equation Modelling in Practice: A Review and Recommend Two-step Approach. Psychol. Bull. 1988, 103, 411-423. [CrossRef]

35. Mulaik, S.A.; James, L.R.; Van Alstine, J.; Bennet, N.; Lind, S.; Stilwell, C.D. Evaluation of Goodness-of-Fit Indices for Structural Equation Models. Psychol. Bull. 1989, 105, 430-445. [CrossRef]

36. Bollen, K.A. Structural Equations with Latent Variables; Wiley series in probability and mathematical statistics; John Wiley \& Sons: New York, NY, USA, 2014.

37. Joreskog, K.G.; Sorbom, D. LISREL 8: Structural Equation Modeling with the SIMPLIS Command Language; Scientific Software International: Chicago, IL, USA, 1993.

38. Browne, M.W.; Cudeck, R. Alternative ways of assessing model fit. In Testing Structural Models; Bollen, K.A., Long, J.S., Eds.; Sage: Newbury Park, CA, USA, 1993; pp. 136-162.

39. Steiger, J.H. Understanding the limitations of global fit assessment in structural equations modelling. Personal. Individ. Differ. 2007, 42, 893-898. [CrossRef]

40. Hooper, D.; Coughlan, J.; Mullen, M.R. Structural Equation Modelling: Guidelines for Determining Model Fit. Electron. J. Bus. Res. Methods 2008, 6, 53-60.

41. George, D.; Mallery, P. SPSS for Windows Step by Step: A Simple Guide and Reference 11.0 Update, 4th ed.; Allyn \& Bacon: Boston, MA, USA, 2003.

42. Lu, C.S.; Lai, K.H.; Cheng, T.C.E. Application of Structural Equation Modeling to Evaluate the Intention of Shippers to Use Internet Services in Liner Shipping. Eur. J. Oper. Res. 2007, 180, 845-867. [CrossRef]

43. Hu, L.; Bentler, P.M. Cutoff criteria for fit indexes in covariance structure analysis: Conventional criteria versus new alternatives. Struct. Equ. Model. 1999, 6, 1-55. [CrossRef] 